\title{
ANALISIS PERUBAHAN LUAS HUTAN DI JAWA TIMUR MENGGUNAKAN CITRA SATELIT TERRA MODIS ANTARA TAHUN 2007 - 2011
}

(Studi Kasus : Daerah Propinsi Jawa Timur Berdasarkan Indek Vegetasi NDVI dan EVI)

\author{
Basori, Bangun Muljo Sukojo \\ Program Studi Teknik Geomatika FTSP-ITS, Kampus ITS Sukolilo, Surabaya, 60111 \\ Email : basori@rocketmail.com, bangunms@gmail.com
}

\begin{abstract}
Abstrak
Indonesia merupakan negara yang memiliki hutan yang luas. Luas hutan tersebut mengalami penurunan akibat penebangan secara illegal ataupun karena kebakaran hutan. Salah satu propinsi yang memiliki hutan yang luas adalah Jawa Timur. laju kerusakan hutan di Jawa Timur mengalami peningkatan dikarenakan human error dalam pengelolaan hutan.

Dalam penelitian ini, pemetaan hutan dilakukan dengan menggunakan metode penginderaan jauh dengan memanfaatkan data citra satelit Terra MODIS dengan menggunakan algoritma NDVI dan EVI. Identifikasi hutan dilakukan dengan memanfaatkan nilai indek vegetasi yang dihasilkan dari algoritma NDVI dan EVI.

Penelitian ini menunjukkan bahwa nilai indek vegetasi dengan menggunakan algoritma NDVI lebih stabil jika dibandingkan dengan algoritma EVI. Luas area hutan pada musim hujan lebih besar dibandingkan luas area hutan pada musim kemarau karena pada musim kemarau terdapat jenis vegetasi yang menggugurkan daunnya. Perubahan hutan tiap tahun hasil dari pengolahan citra memiliki sifat yang tidak stabil dikarenakan tiap citra memiliki nilai spektral yang berbeda akibat dari perbedaan posisi satelit saat pengambilan data dan kondisi atmosfer saat pengambilan data. Hasil pengolahan citra menggunakan algoritma EVI memiliki tingkat keakuratan paling baik yaitu sebesar $86,4 \%$ pada musim hujan. Sedangkan hasil pengolahan citra menggunakan algoritma NDVI memiliki tingkat keakuratan sangat rendah karena memiliki selisih sangat tinggi ketika dibandingkan dengan data dari Dinas Kehutanan Propinsi Jawa Timur.
\end{abstract}

Kata Kunci : Terra, MODIS, Indek Vegetasi, NDVI, EVI

\section{PENDAHULUAN}

\section{Latar Belakang}

Bencana Lumpur Lapindo yang terjadi di Kecamatan Porong sejak tahun 2006 lalu mengakibatkan banyak timbulnya dampak negatif bagi lingkungan sekitar terutama masyarakat sekitar kecamatan tersebut. Pada awalnya, semburan lumpur terjadi pada tanggal 27 Mei 2006 di dekat sumur bor Banjar Panji milik PT Lapindo Brantas Inc., Kecamatan Porong, Kabupaten Sidoarjo. Namun pada tanggal 1 Juni 2006, muncul sumber baru di rumah penduduk Balong Nongo. Beberapa sumber telah berhenti, tetapi ada satu yang masih menyemburkan lumpur hingga sekarang yaitu di dekat sumur bor.

Sampai saat ini semburan Lumpur Lapindo tersebut belum dapat dihentikan, sehingga daerah yang tergenang lumpur semakin meluas dan dampak yang ditimbulkanya pun semakin besar. Volume keluarnya lumpur mencapai $150.000 \mathrm{~m} 3$ per hari. Akibatnya, berbagai permasalahan muncul, diantaranya tenggelamnya pemukiman masyarakat, persawahan, jalan raya, areal industri, jaringan listrik, jaringan telekomunikasi, sehingga masyarakat harus mengungsi ke daerah yang tidak tergenang lumpur.

Salah satu dampak yang ditimbulkan oleh luapan lumpur Sidoarjo adalah terjadinya land subsidence (penurunan tanah). Land subsidence didefinisikan sebagai penurunan muka tanah sebagai fungsi dari waktu, atau dapat juga disebut deformasi vertikal, yang artinya perubahan kedudukan vertikal dari permukaan tanah terhadap bidang referensi yang dianggap tetap (Hamdani 2004, lihat juga pada Cahyono 2010). Adapun penyebab land subsidence adalah pengambilan air tanah yang berlebihan (groundwater over exploitation), keluarnya gas 
dan lumpur secara massive dari dalam tanah ke permukaan, penurunan karena beban bangunan, penurunan karena adanya konsolidasi alamiah dari lapisan-lapisan tanah, serta penurunan karena gaya-gaya tektonik (Cahyono, 2010).

Kebanyakan penurunan permukaan tanah (land subsidence) terjadi secara perlahan, sehingga dalam analisisnya perlu dilakukan secara berkala (fungsi waktu). Pemantauan land subsidence dapat dilakukan dengan beberapa metode, salah satunya adalah dengan Global Positioning System (GPS). Dengan dilakukannya pemantauan land subsidance tesebut diharapkan dapat mengetahui seberapa besar penurunan tanah yang ada disekitar semburan lumpur.

\section{Perumusan Masalah}

Dari latar belakang di atas, maka perumusan masalah yang akan dilaksanakan dalam penelitian Tugas Akhir ini adalah "Bagaimana cara memetakan dan menganalisis kondisi perubahan hutan primer di Jawa Timur menggunakan citra satelit Terra MODIS antara tahun 2007 - 2011?"

\section{Batasan Masalah}

Batasan masalah dari penelitian ini sebagai berikut:

1. Citra satelit yang digunakan adalah citra satelit Terra MODIS antara tahun 2007 - 2011

2. Citra yang digunakan tiap tahun sebanyak dua citra, yaitu satu di musim hujan dan satu di musim kemarau.

3. Daerah penelitian di Propinsi Jawa Timur

4. Pemetaan hutan menggunakan parameter nilai spektral vegetasi.

\section{Tujuan Penelitian}

Tujuan penelitian ini adalah :

1. Memetakan daerah hutan di Propinsi Jawa Timur dengan parameter nilai spektral vegetasi.

2. Menganalisis kondisi perubahan hutan di Propinsi Jawa Timur antara tahun 2007 - 2011

\section{METODOLOGI PENELITIAN}

\section{Lokasi Penelitian}

Penelitian tentang analisa perubahan hutan di Jawa Timur dengan menggunakan parameter nilai spektral di Propinsi Jawa Timur menggunakan citra satelit Terra MODIS, yang diambil pada tahun 2007 sampai tahun 2011. Propinsi Jawa Timur merupakan propinsi di Pulau Jawa yang terletak pada 111,0 - $-114,4$ ㅇ BT dan 7,12ㅇ - 8,48응 LS. Batas-batas wilayah Propinsi Jawa Timur , di sebelah utara berbatasan dengan Laut Jawa (Pulau Kalimantan), sebelah timur berbatasan dengan Selat Bali (Pulau Bali), sebelah selatan berbatasan dengan Samudera Indonesia, sebelah barat berbatasan langsung dengan Propinsi Jawa Tengah.

\section{Data Dan Peralatan}

\section{- Data}

Data yang digunakan dalam penelitian ini adalah:

1. Data citra satelit Terra MODIS antara tahun 2007 - 2011 di Propinsi Jawa Timur.

2. Data peta Rupa Bumi Indonesia (RBI) Propinsi Jawa Timur skala $1: 250.000$.

3. Data peta persebaran hutan di Propinsi Jawa Timur.

\section{- Peralatan}

Peralatan yang digunakan dalam penelitian ini adalah:

1. Perangkat Keras (Hardware)
a. Laptop
b. GPS Handheld

2. Perangkat Lunak (Software)

a. ENVI 4.6.1

b. Matlab 7.0.1

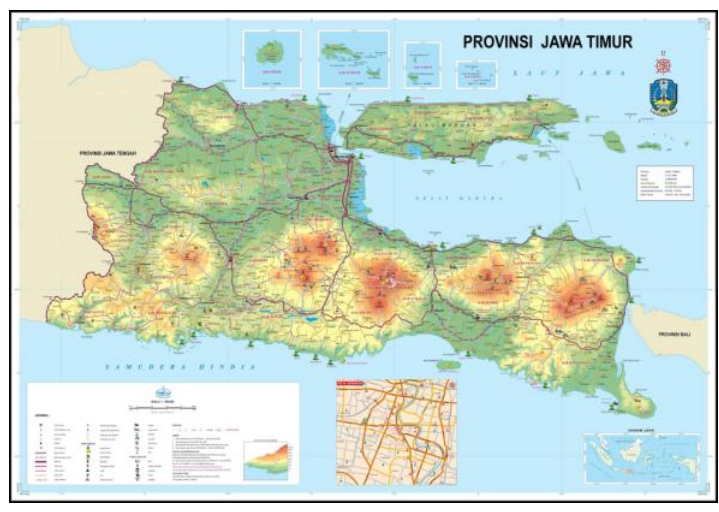

Gambar 2.1 Lokasi Penelitian 


\section{Diagram Alir Pengolahan Data}

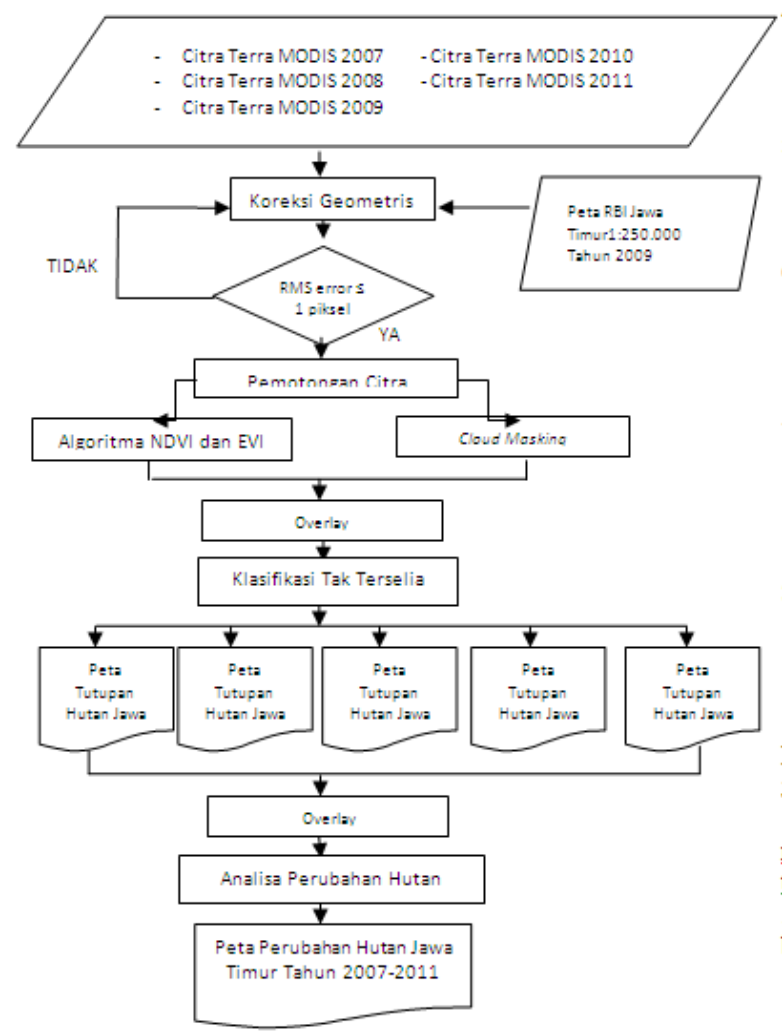

Gambar 2. Diagram Tahap Pengolahan Data

Penjelasan dari diagram alir penelitian di atas adalah :

1. Buka data citra satelit Terra yang akan diolah menggunakan software ENVI.

2. Sebelum dilakukan koreksi geometrik, citra terlebih dahulu dilakukan georeference untuk menetapkan band - band dan datum yang digunakan. Kemudian dilakukan proses koreksi geometrik. Jaring yang digunakan dalam koreksi geometrik dihitung kekuatan jaringnya (Strength of Figure) dimana nilai kekuatan jaring bernilai semakin baik jika mendekati 0.

4. Citra yang telah terkoreksi geometrik kemudian di-cropping dengan menggunakan fasilitas Region of Interest (ROI) pada software ENVI.

5. Cloud masking yang merupakan proses identifikasi awan menggunakan panjang gelombang pada band 3 sehingga awan dapat dipisahkan.

6. Algoritma NDVI dan EVI digunakan untuk memperoleh nilai spektral indek vegetasi yang digunakan untuk mengidentifikasi daerah hutan.

7. Proses klasifikasi dengan menganalisis sejumlah piksel berdasarkan digital numbernya. Proses ini dilakukan dengan menggunakan fasilitas band threshold to ROI pada ENVI.

8. Pada tahap analisis, dilakukan analisa tentang perubahan daerah hutan yang terjadi dan membandingkan hasil pengolahan citra satelit Terra MODIS yang menggunakan algoritma NDVI dan EVI.

9. Dari pengolahan data citra dan analisis yang dilakukan diperoleh hasil akhir peta perubahan hutan Jawa Timur tahun 2007 2011

\section{HASIL DAN PEMBAHASAN}

\section{Pengumpulan Data}

Data yang diambil dari lapangan diolah dengan menggunakan software TOPCON TOOLS. Seluruh data yang telah diolah dapat dilihat dalam tabel berikut:

\begin{tabular}{|c|c|c|c|}
\hline No & Tahun & Nama Data & Keterangan \\
\hline 1 & 2007 & $\begin{array}{c}\text { MOD02HKM.A2007016.0255 } \\
.005 .2010188061743\end{array}$ & Terra MODIS \\
\hline 2 & 2007 & $\begin{array}{c}\text { MOD02HKM.A2007192.0255 } \\
.005 .2010201141917\end{array}$ & Terra MODIS \\
\hline 3 & 2008 & $\begin{array}{c}\text { MOD02HKM.A2008165.0245 } \\
.005 .2010239182631\end{array}$ & Terra MODIS \\
\hline 4 & 2008 & $\begin{array}{c}\text { MOD02HKM.A2008268.0250 } \\
.005 .2010250124132\end{array}$ & Terra MODIS \\
\hline 5 & 2009 & $\begin{array}{c}\text { MOD02HKM.A2009123.0220 } \\
.005 .2010241100058\end{array}$ & Terra MODIS \\
\hline 6 & 2009 & $\begin{array}{c}\text { MOD02HKM.A2009289.0320 } \\
.005 .2010253041753\end{array}$ & Terra MODIS \\
\hline 7 & 2010 & $\begin{array}{c}\text { MOD02HKM.A2010067.0240 } \\
.005 .2010265022431\end{array}$ & Terra MODIS \\
\hline 8 & 2010 & $\begin{array}{c}\text { MOD02HKM.A2010173.0315 } \\
.005 .2010173133255\end{array}$ & Terra MODIS \\
\hline 9 & 2011 & $\begin{array}{l}\text { MOD02HKM.A2011052.0250 } \\
.005 .2011053014106\end{array}$ & Terra MODIS \\
\hline 10 & 2011 & $\begin{array}{c}\text { MOD02HKM.A2011144.0315 } \\
.005 .2011144133621\end{array}$ & Terra MODIS \\
\hline
\end{tabular}

\section{Koreksi Geometrik dan Strength Of Figure}

Untuk koreksi geometrik diberikan toleransi nilai RMSE $\leq 1$ piksel dan untuk jaring titik kontrol ditentukan dengan meletakkan titik-titik kontrol yang merata mencakup daerah studi dengan nilai toleransi SOF mendekati nol. Berikut hasil perhitungan RMSE dan SOF. 
Tabel 2. Rata-Rata RMSE dan SOF

\begin{tabular}{|c|c|c|c|c|}
\hline No & Nama Data & $\begin{array}{l}\text { Nilai } \\
\text { SOF }\end{array}$ & $\begin{array}{c}\text { Nilai } \\
\text { RMSE } \\
\text { Rata-Rata }\end{array}$ & Keterangan \\
\hline 1 & $\begin{array}{l}\text { MOD02HKM.A20 } \\
07016.0255 .005 . \\
2010188061743\end{array}$ & 0,00125 & 0,532632 & $\begin{array}{c}\text { Terra } \\
\text { MODIS }\end{array}$ \\
\hline 2 & $\begin{array}{l}\text { MOD02HKM.A20 } \\
07192.0255 .005 . \\
2010201141917\end{array}$ & 0,00168 & 0,440344 & $\begin{array}{c}\text { Terra } \\
\text { MODIS }\end{array}$ \\
\hline 3 & $\begin{array}{l}\text { MOD02HKM.A20 } \\
08165.0245 .005 . \\
2010239182631\end{array}$ & 0,00168 & 0,456131 & $\begin{array}{c}\text { Terra } \\
\text { MODIS }\end{array}$ \\
\hline 4 & $\begin{array}{l}\text { MOD02HKM.A20 } \\
08268.0250 .005 . \\
2010250124132\end{array}$ & 0,00168 & 0.405068 & $\begin{array}{c}\text { Terra } \\
\text { MODIS }\end{array}$ \\
\hline 5 & $\begin{array}{l}\text { MOD02HKM.A20 } \\
09123.0220 .005 . \\
2010241100058\end{array}$ & 0,00168 & 0,536805 & $\begin{array}{c}\text { Terra } \\
\text { MODIS }\end{array}$ \\
\hline 6 & $\begin{array}{l}\text { MOD02HKM.A20 } \\
09289.0320 .005 . \\
2010253041753\end{array}$ & 0,00125 & 0,562886 & $\begin{array}{c}\text { Terra } \\
\text { MODIS }\end{array}$ \\
\hline 7 & $\begin{array}{l}\text { MOD02HKM.A20 } \\
10067.0240 .005 . \\
2010265022431\end{array}$ & 0,00168 & 0,67364 & $\begin{array}{l}\text { Terra } \\
\text { MODIS }\end{array}$ \\
\hline 8 & $\begin{array}{l}\text { MOD02HKM.A20 } \\
10173.0315 .005 . \\
2010173133255\end{array}$ & 0,00125 & 0,508134 & $\begin{array}{c}\text { Terra } \\
\text { MODIS }\end{array}$ \\
\hline 9 & $\begin{array}{l}\text { MOD02HKM.A20 } \\
11052.0250 .005 . \\
2011053014106\end{array}$ & 0,00168 & 0,740278 & $\begin{array}{c}\text { Terra } \\
\text { MODIS }\end{array}$ \\
\hline 10 & $\begin{array}{l}\text { MOD02HKM.A20 } \\
11144.0315 .005 . \\
2011144133621\end{array}$ & 0,00168 & 0,42436 & $\begin{array}{c}\text { Terra } \\
\text { MODIS }\end{array}$ \\
\hline
\end{tabular}

Hasil Pengolahan Menggunakan Algoritma NDVI Proses pengolahan citra dengan menggunakan algoritma NDVI menghasilkan nilai spektral indek vegetasi untuk seluruh daerah penelitian. Untuk itu dilakukan klasifikasi untuk mendefinisikan daerah hutan. Hasil dari klasifikasi tersebut sebagai berikut:

Tabel 3. Rata-Rata RMSE dan SOF

\begin{tabular}{ccc}
\hline \multirow{2}{*}{ Tahun } & \multicolumn{2}{c}{ Musim } \\
& Hujan & Kemarau \\
\hline 2007 & 1.655 .650 & 2.105 .625 \\
2008 & 2.090 .900 & 643.950 \\
2009 & 2.613 .275 & 419.625 \\
2010 & 1.730 .675 & 2.419 .050 \\
2011 & 1.285 .250 & 1.624 .925 \\
\hline
\end{tabular}

Dalam tabel 3.3 terlihat bahwa pada tahun 2007 terjadi kenaikan area hutan dari musim hujan ke musim kemarau, hal ini dikarenakan data yang digunakan belum memasuki musim kemarau. Sedangkan pada tahun 2008 dan 2009 terjadi penurunan area hutan karena pada musim kemarau terdapat beberapa hutan yang vegetasinya menggugurkan daunnya.

Tabel 4. Nilai Indek Vegetasi Hutan Jawa Timur dengan algoritma NDVI

\begin{tabular}{ccccc}
\hline \multirow{2}{*}{ Tahun } & \multicolumn{2}{c}{ Musim } \\
& Min & Maks & Min & Maks \\
\hline 2007 & 0,6 & 0,814808 & 0,6 & 0,833623 \\
2008 & 0,6 & 0,834168 & 0,6 & 0,79398 \\
2009 & 0,6 & 0,801644 & 0,6 & 0,71854 \\
2010 & 0,6 & 0,805267 & 0,6 & 0,812525 \\
2011 & 0,6 & 0,811377 & 0,6 & 0,781021 \\
\hline
\end{tabular}

Dalam tabel 4. terlihat bahwa nilai indek vegetasi hutan memiliki nilai minimal yang stabil yaitu 0,6 dan memiliki nilai maksimal yang bervariasi.

\section{Hasil Pengolahan Menggunakan Algoritma EVI}

Proses pengolahan citra dengan menggunakan algoritma EVI menghasilkan nilai spektral indek vegetasi untuk seluruh daerah penelitian. Hasil dari klasifikasi sebagai berikut :

Tabel 5. Luas Area Hutan Berdasarkan Algoritma EVI (Ha)

\begin{tabular}{ccc}
\hline \multirow{2}{*}{ Tahun } & \multicolumn{2}{c}{ Musim } \\
& Hujan & Kemarau \\
\hline 2007 & 2.687 .725 & 2.250 .050 \\
2008 & 2.032 .225 & 1.160 .475 \\
2009 & 2.002 .075 & 1.449 .275 \\
2010 & 1.168 .075 & 2.545 .900 \\
2011 & 1.471 .825 & 2.131 .500 \\
\hline
\end{tabular}

Dalam tabel 5. terlihat bahwa pada tahun 2010 dan 2011 terjadi kenaikan dari musim hujan ke musim kemarau. Sedangkan pada tahun 2008 dan 2009 terjadi penurunan area hutan. 
Tabel 6. Nilai Indek Vegetasi Hutan Jawa Timur dengan Algoritma EVI

\begin{tabular}{|c|c|c|c|c|}
\hline \multirow{3}{*}{ Tahun } & \multicolumn{4}{|c|}{ Musim } \\
\hline & \multicolumn{2}{|c|}{ Hujan } & \multicolumn{2}{|c|}{ Kemarau } \\
\hline & Min & Maks & Min & Maks \\
\hline 2007 & 0,48 & 0,830446 & 0,4 & 0,74296 \\
\hline 2008 & 0,45 & 0,789857 & 0,45 & 0,845296 \\
\hline 2009 & 0,75 & 1,170274 & 0,45 & 0,803464 \\
\hline 2010 & 0,8 & 1,1093 & 0,45 & 0,848789 \\
\hline 2011 & 0,55 & 0,847796 & 0,5 & 0,847796 \\
\hline
\end{tabular}

Dalam tabel 6. terlihat bahwa nilai indek vegetasi hutan memiliki nilai minimal yang stabil yaitu 0,45 dan memiliki nilai maksimal yang bervariasi.

Tabel 7. Daftar Curah Hujan Tahun 2007-2011

\begin{tabular}{cccccc}
\hline \multirow{2}{*}{ Bulan } & \multicolumn{5}{c}{ Curah Hujan (mm) } \\
& $\mathbf{2 0 0 7}$ & $\mathbf{2 0 0 8}$ & $\mathbf{2 0 0 9}$ & $\mathbf{2 0 1 0}$ & $\mathbf{2 0 1 1}$ \\
\hline Januari & 122 & 288 & 305 & 324 & 330 \\
Februari & 330 & 448 & 384 & 335 & 332 \\
Maret & 315 & 692 & 265 & 266 & 250 \\
April & 250 & 206 & 115 & 308 & 248 \\
Mei & 78 & 130 & 157 & 229 & 137 \\
Juni & 61 & 28 & 33 & 274 & 79 \\
Juli & 18 & - & 65 & 66 & 62 \\
Agustus & 2 & - & - & 108 & 125 \\
September & 2 & 12 & 33 & 283 & 89 \\
Oktober & 62 & 107 & 16 & 374 & 114 \\
November & 158 & 365 & 155 & 525 & 343 \\
Desember & 581 & 22 & 76 & 259 & 285 \\
\hline
\end{tabular}

Dalam tabel 6. dan 7. terlihat bahwa curah hujan pada bulan Januari tahun 2007 memiliki curah hujan sangat tinggi sehingga mengakibatkan meningkatnya nilai indek vegetasi. Sedangkan pada bulan Juli, curah hujan menurun drastis sehingga nilai indek vegetasi juga mengalami penurunan.

\section{Hasil Perubahan Area Hutan}

Hasil pengolahan dari algoritma NDVI dan EVI dapat digunakan untuk mendapatkan perubahan area hutan di Jawa Timur antara tahun 2007 2011. Hasil perubahan hutan tiap tahun sebagai berikut:
Tabel 8. Luas Area Hutan 2007-2011

\begin{tabular}{cccccc}
\hline \multirow{2}{*}{ Tahun } & \multicolumn{5}{c}{ Dinas } \\
& Kehutanan & Hujan & Kemarau & Hujan & Kemarau \\
\hline 2007 & $1.363 .719,00$ & 1.655 .650 & 2.105 .625 & 2.687 .725 & 2.250 .050 \\
2008 & $1.339 .812,80$ & 2.090 .900 & 643.950 & 2.032 .225 & 1.160 .475 \\
2009 & $1.304 .925,00$ & 2.613 .275 & 419.625 & 2.002 .075 & 1.449 .275 \\
2010 & $1.364 .399,61$ & 1.730 .675 & 2.419 .050 & 1.168 .075 & 2.545 .900 \\
2011 & $1.357 .206,30$ & 1.285 .250 & 1.624 .925 & 1.471 .825 & 2.131 .500 \\
\hline
\end{tabular}

\section{KESIMPULAN DAN SARAN}

\section{Kesimpulan}

Berdasarkan hasil penelitian tentang pemetaan hutan menggunakan algoritma NDVI dan EVI, maka didapatkan beberapa kesimpulan akhir dari penelitian ini, yaitu:

a. Nilai indek vegetasi dengan menggunakan algoritma NDVI memiliki nilai minimal dan nilai maksimal lebih stabil jika dibandingkan dengan EVI

b. Luas area hutan juga dipengaruhi perubahan musim. Perubahan hutan tiap tahun hasil dari pengolahan citra memiliki sifat yang tidak stabil, baik menggunakan NDVI ataupun EVI.

c. Hasil algoritma EVI menunjukkan bahwa pada tahun 2009 - 2010 terjadi penurunan area hutan seluas 834.400 ha pada musim hujan, sedangkan pada musim kemarau terjadi peningkatan sebesar 1.096.625 ha. Hasil algoritma NDVI juga menunjukkan bahwa pada tahun 2009-2010 terjadi penurunan sebesar 882.600 ha pada musim hujan dan pada musim kemarau terjadi peningkatan sebesar 1.999.325 ha.

\section{Saran}

a. Perlu dilakukan pemetaan hutan dengan menggunakan data yang memiliki tingkat ketelitian lebih tinggi.

b. Untuk penelitian selanjutnya lebih baik menggabungkan data citra Terra MODIS dengan data citra satelit yang memiliki resolusi spasial yang lebih teliti sehingga dapat diketahui jenis - jenis hutan di Jawa Timur.

c. Untuk mendapatkan nilai spektral hutan dengan ketelitian yang baik, digunakan data lapangan dengan mengukur nilai spektral hutan menggunakan spektrometer. 
d. Perlu dilakukan penelitian untuk mendapatkan algoritma yang lebih spesifik untuk pendefinisian daerah hutan.

\section{DAFTAR PUSTAKA}

Abidin, H. Z., dkk. 2002. Survei Dengan GPS. Jakarta: Pradnya Paramitha.

Arozaq, M. 2008. Penginderaan Jauh (Remote Sensing). <URL:http:www.geografi.ums.ac.id/ebook/ .../arcview_3x_Analisis_Citra_Arcview.pdf> dikunjungi pada tanggal 21 maret 2012, jam 18.45 .

Anggraini, N. dan Trisakti, B. 2011. Kajian Dampak Perubahan Iklim Terhadap Kebakaran Hutan dan Deforestasi di Propinsi Kalimantan Barat. Jurnal Penginderaan jauh Vol. 8, 2011 : 11-20.

BPKH Wilayah XI Jawa-Madura. 2009. Potret Hutan Propinsi Jawa Timur. Yogyakarta. Balai Pemantapan Kawasan Hutan Wilayah XI Jawa-Madura.

Duong, N.D. 2004. Land Cover Mapping Of Vietnam Using Modis 500m 32-Day Global Composites. International Symposium on Geoinformatics for Spatial Infrastructure Development in Earth and Allied Sciences 2004. Hanoi : Institute of Geography.

Hervina. 2011. Harian Analisa : Fungsi Hutan untuk Kehidupan.

<URL:http://www.analisadaily.com/news/r ead/2011/08/14/8546/fungsi_hutan_untu k_kehidupan/> dikunjungi pada tanggal 13 Februari 2012, jaum 9.56.

Huete, A., Justice, C. dan Leeuwen, W.1999. Modis Vegetation Index (Mod 13) Algorithm Theoretical Basis Document. <URL:http://modis.gsfc.nasa.gov/ > dikunjungi pada tanggal 15 Februari 2012, jam 6.45.

Janssen, L.F.L and Huurneman C.G. 2001. Principles of Remote Sensing. ITC Educational Texbooks Series. ITC, Enshede, Netherlands.
Lillesand dan Kiefer. 1997. Penginderaan Jauh dan Interpretasi Citra. Dulbahri (Penerjemah). Gadjah Mada University Press, Yogyakarta.

Pentury, R. 1997.Algoritma pendugaan Konsentrasi klorofil di perairan teluk ambon menggunakan citra Landsat TM. Program studi Teknik Kelautan Program Pasca Sarjana IPB : Bogor.

Purnawati, N.P. 2010. Analisa Potensi Lahan Pertanian dengan Menggunakan Teknologi Penginderaan Jauh dan Sistem Informasi Geografis di Kabupaten Tabanan dan Badung-Bali. Collection of Student Research vol 1Mei 2010:112-120.

Rahmawaty, S. 2004. Hutan : Fungsi dan Peranannya bagi Masyarakat. Program IImu Kehutanan. Universitas Sumatera Utara. <URL:http://www.repository.usu.ac.id/bits tream/123456789/.../hutanrahmawaty6.pdf /> dikunjungi pada tanggal 13 Februari 2012, jam 9.16.

Rusdiyatmoko, A. dan Zubaidah, A. 2005. Analisis Spektral Data Modis untuk Pemantauan Hutan/Lahan (Studi Kasus Propinsi Sumatra Selatan). Pertemuan IImiah Tahunan MAPIN XIV “Pemanfaatan Efektif Penginderaan Jauh Untuk Peningkatan Kesejahteraan Bangsa". Institut Teknologi Sepuluh Nopember Surabaya, 14 - 15 September 2005.

Sardiyoko. 2003. Kerusakan Hutan di Jawa Timur. <URL:http://www.groups.yahoo.com/grou p/lingkungan/message/17457> dikunjungi pada tanggal 13 Februari, jam 12.23.

Sardiyoko. 2010. Kerusakan Hutan di Jawa Timur Siapa yang Bertanggung Jawab. <URL:http://canvasing.wordpress.com/ > dikunjungi pada tanggal 22 Maret 2012, jam 7.08.

Siddik, A. 2008. Karakteristik Citra Satelit. Medan. Universitas Sumatera Utara

Zain, AS. 1996. Hukum lingkungan Konservasi Hutan. Penerbit Rineka Cipta. Jakarta. 